\title{
Genetic Variation in Bell Peppers (Capsicum annuum L.) Collected from Iraqi Local Markets by Using AFLP Marker
}

\author{
Ihsan A. Hussein and Shaymaa S. Mahdi \\ Department of Biology, College of Education for Pure Science/Ibn-Al-Haithim, University of Baghdad, \\ Baghdad-Iraq (Corresponding author e-mail: ihsan1964@yahoo.com)
}

\begin{abstract}
Genetic variation was studied in 20 local and imported samples of bell pepper fruits (Capsicum annиuт L.), which collected from Iraqi local markets by using amplified fragment length polymorphism (AFLP) marker. Three selective primer combinations were used in all samples. The first selective primer combination $\left(E_{A C G} M_{A G G}\right)$ produced 4 bands for the studied bell pepper fruits with 3 monomorphic bands in each sample, except the orange and yellow Jordanian bell pepper samples, which produced 4 bands one of them polymorphic band with $25 \%$ ratio and $21.43 \%$ primer efficiency with $100 \%$ discriminatory power. The second selective primer combination $\left(E_{A A G} / M_{A A T}\right)$ produced 4 monomorphic bands in each sample with no polymorphic bands with $28.57 \%$ primer efficiency and $0 \%$ discriminatory power, whereas the third selective primer combination $\left(E_{A C A} / M_{C T G}\right)$ produced 7 monomorphic bands in each sample, except the Iraqi/Balad green bell pepper, which produced 3 monomorphic bands with no polymorphic bands and the primer efficiency is 50\% with 0\% discriminatory power. The results of dendrogram of the studied samples by using Jaccard coefficient for genetic similarity was distributed the samples into 3 main groups. The first group was included the red and orange Jordanian bell pepper fruits samples, whereas the second group included the Iraqi/Balad green bell pepper and the third group included the rest samples. The results of this distribution revealed a high similarity between red and orange Jordanian bell pepper and the other bell pepper samples, except Iraqi/Balad green bell pepper with 0.94 values. This value is the higher, whereas the similarity with the Iraqi/Balad green bell pepper is 0.68 values. The genetic distance between studied samples revealed the highest values between red and orange Jordanian bell pepper and the Iraqi/Balad green bell pepper with 2.236 values.
\end{abstract}

Keywords: AFLP, Bell pepper, Capsicum annuum L., Genetic variation

\section{Introduction}

Pepper belongs to the family Solanaceae and it is included 27-30 species, however only five species are domesticated which are Capsicum annuum, $C$. baccatum, $C$. chinense, $C$. frutescens and $C$. pubescens [1], [2]. It is believed that these five domesticated species are derived from three distinct genetic species while $C$. pubescens and $C$. baccatum derived from two independent species, and $C$. annuum, $C$. chinense and $C$. frutescens derived from species which is may be descended from an independent or non-independent type; also it is believed that South America is the main source of pepper species [3], [4]. The pepper C. annuиm is one of the most important of other five species and includes a hot genre Pungent (Hot) and cold type sweet (mide). The hot pepper contains alkaloid compounds which are responsible for the hot taste called Capsaicinoids; this has many medical benefits as well as its importance in the pharmaceutical industry. Capsaicinoids are not found in the sweet pepper; however it's being an important source of nutrients such as carotenoids, polyphenols and vitamins [5]. The classification of this genus of pepper is difficult sometimes when dependents on its morphoagronomic characteristics due to the effecting the morphological characteristics by environmental factors [2], and also there is no accuracy in the distinguishing between closely genetic types [6]. The pepper Capsicum annuит L. is a type of vegetables with different types, with high nutritional value. Furthermore, it is an important source of vitamins A, C, and E, many antioxidant agents, which used as a natural flavor and colorful 
for foods, as well as has multiple medical benefits including anti-inflammatory, anti-allergic anti-allergenic and anti-carcinogenesis agent. It was found that using the mature red peppers reduced the risk of cancer [5], [7], [8]. The genome of Capsicum pepper consists of 12 pairs of chromosomes with the size haploid chromosomal group estimated 3.3-3.6G base pair [9], [10]. The information about genetic variations help to increase the efficiency, development and improvement of the species in pepper, as many farmers turned to crops that with high production qualities and desired properties rather than the traditional cultivars [11], [12], although the peppers is more vegetables farmed, there is no sufficient genetically and molecular studies in comparison to other crops, due to the difficulties to find a good genetic findings; DNA markers are good markers to study the pepper because it's highly conserved, especially the cultivated pepper which is less in variation than wild types, as well as the sweet pepper with a large fruit shows little variation compared to the diversity of the small fruit in chili [13]. The genetic diversity and evolution have been studied and diagnosis of classes of the pepper as well using the phenotypic chromosomes [4], [14], analysis of allozymes [15] and electrophoresis of soluble proteins [17], [18], [19], [20], [21] and isozyme analysis [22]. The analysis observed that the diversity in the isozyme was low in the varieties of C. апnиum [18], thus the analysis of isozyme is using in the breeding programs of pepper, especially when combing different types of Capsicum in such programs. Amplified fragment length polymorphism (AFLP) technique is dependent on the detection of DNA fragments that cutting with restriction enzymes through amplification using Polymerase chain reaction (PCR) [23]. This technique has been applied to the analysis of diversity between varieties in various fruits and types of walnut trees, also this technique showed a high significant levels in the detection of DNA polymorphism as well as one of the most techniques promising fingerprinting studies, genetic mapping and studies the genetic variations. Moreover, the benefits of this technique is be given a large number of amplified DNA fragments in each PCR reaction [24]. This technique has been used in many genetic variations in the pepper studies [6], [11], [25], [26], [27], [28], [29]. The study aimed to determine the possibility to detect polymorphism in the fruits of the large sweet pepper (bell pepper) that locally grown and imported from other countries by using AFLP technique in the detection of genetic variation in the studied samples and to study the genetic relationship between the studied fruits of pepper using Unweight Pair Group Method with Arithmetic Mean (UPGMA) analysis.

\section{Materials and Methods}

\subsection{Plant Materials}

Twenty samples of bell pepper fruits were collected from markets in Baghdad-Iraq. Many samples were imported from other countries and no information was available if these samples were cultivated or genetically modified (Table 1).

TABLE I: Samples of bell pepper (Capsicum annuum L.) with their Country of Origin

\begin{tabular}{|c|c|c|}
\hline Sample No. & Country of pepper origin & Pepper color \\
\hline 1 & Jordan & Orange \\
\hline 2 & Jordan & Red \\
\hline 3 & Jordan & Yellow \\
\hline 4 & Jordan & Green \\
\hline 5 & Spain & Green \\
\hline 6 & Iraq/Balad & Green \\
\hline 7 & Iraq/Yousifia & Red \\
\hline 8 & China & Green \\
\hline 9 & Iraq/Souwyera & Orange \\
\hline 10 & China & Green \\
\hline 11 & China & Red \\
\hline 12 & Spain & Orange \\
\hline 13 & Iran & Yellow \\
\hline 14 & Iran & Orange \\
\hline 15 & Iran & Yellow \\
\hline 16 & Italy & Red \\
\hline 17 & Italy & Red \\
\hline 18 & Spain & Green \\
\hline 19 & Spain & \\
\hline 20 & Iran & \\
\hline
\end{tabular}




\subsection{DNA Extraction}

DNA from bell pepper was extracts by using Kang and Yang [30] method with some modification. About $1 \mathrm{gm}$ from each sample was dried by using liquid nitrogen. Each sample was transferred to $1.5 \mathrm{ml}$ microfuge tube and homogenized in $100 \mu \mathrm{l}$ of DNA extraction buffer $(100 \mathrm{mM}$ Tris-HCl pH7.5, 50mM EDTA pH7.5, 500mM $\mathrm{NaCl}$ and $10 \mathrm{mM} \beta$-mercaptoethanol $\mathrm{pH} 7.5$ ) using a hand-operated homogenizer with a plastic pestle for 15 20 sec. After an initial homogenization, another $300 \mu \mathrm{l}$ of DNA extraction buffer were added and homogenized with the same homogenizer for $15 \sim 20 \mathrm{sec}$. Then $40 \mu \mathrm{l}$ of $20 \%$ SDS were added and vortex for $30 \mathrm{~s}$. The samples were incubated at $65^{\circ} \mathrm{C}$ for $15 \mathrm{~min}$ for cell lysis. Ten microliter from stock solution $(10 \mathrm{mg} \backslash \mathrm{ml})$ of DNase-free RNase A was added and incubation was done under $37^{\circ} \mathrm{C}$ for $60 \mathrm{~min}$. For protein removal a $200 \mathrm{mg}$ of Proteinase $\mathrm{K}$ enzyme was added and the mixture was incubated at $50^{\circ} \mathrm{C}$ for $60 \mathrm{~min}$. An equal volume of phenollchloroformlisoamyl alcohol $(25: 24: 1)$ was added to the samples, mixed by vortex for $30 \mathrm{sec}$, and then centrifuged at 13,000 g for $3 \mathrm{~min}$ at $4^{\circ} \mathrm{C}$. The supernatant was transferred to a fresh tube and extracted one more time with phenol/chloroform/isoamyl alcohol (25:24:1) and centrifuged at $13,000 \mathrm{~g}$ for $10 \mathrm{~min}$ at $4^{\circ} \mathrm{C}$. The supernatant was transferred to a fresh tube and extracted with $500 \mu \mathrm{l}$ of chloroform and then centrifuged at $13,000 \mathrm{~g}$ for $10 \mathrm{~min}$ at $4^{\circ} \mathrm{C}$. The supernatant was transferred to a fresh tube, and a $1 \backslash 10$ of the total volume of the sample $3 \mathrm{M} \mathrm{NaOAc}$ was added. A double volume of $95 \%$ ethanol was added to each sample, mixed well, and the samples were incubated at $-20^{\circ} \mathrm{C}$ for $30 \mathrm{~min}$. The samples were centrifuged at $13,000 \mathrm{~g}$ for $30 \mathrm{~min}$ at $4^{\circ} \mathrm{C}$. The pellet was washed with $70 \%$ ethanol and centrifuged at $13,000 \mathrm{~g}$ for $10 \mathrm{~min}$ at $4^{\circ} \mathrm{C}$. The pellet was dried for 10 min, and resuspended in $100 \mu \mathrm{TE}$ buffer (1 mM Tris- $\mathrm{HCl}, 0.1 \mathrm{mM}$ EDTA $\mathrm{pH} 8)$. The concentration and purity were determined by using Nanodrop (Act Gene, USA). The extract DNA was stored at $-20^{\circ} \mathrm{C}$.

\subsection{AFLP Primers and Adapters}

Primers and adapters for genetic variation study by AFLP marker in bell pepper fruits were used according on [23], [31], and synthesized at Alpha DNA Company (Canada) (Table 2).

TABLE II: The Nucleotide Sequence of Primers and Adapters used in Characterization of 20 Bell Peppers Samples by AFLP Markers

\begin{tabular}{|c|c|}
\hline Primer & Sequence $\left(5^{\prime} \rightarrow 3^{\prime}\right)$ \\
\hline EcoR1 adaptors & 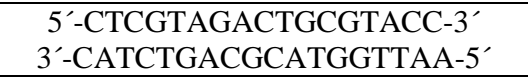 \\
\hline MseI adaptors & 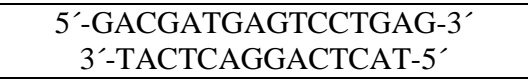 \\
\hline$E c o \mathrm{R} 1$ primer+A $\left(\mathrm{E}_{\mathrm{A}}\right)$ & 5'-GACTGCGTACCAATTC+A-3' \\
\hline MseI primer+C $\left(\mathrm{M}_{\mathrm{C}}\right)$ & 5'-GATGAGTCCTGAGTAA+C-3' \\
\hline $\mathrm{E}_{\mathrm{ACG}}$ & 5'- GACTGCGTACCAATTC +ACG-3' \\
\hline $\mathrm{E}_{\mathrm{AAG}}$ & 5'- GACTGCGTACCAATTC +AAG-3' \\
\hline $\mathrm{E}_{\mathrm{ACA}}$ & 5'- GACTGCGTACCAATTC +ACA-3' \\
\hline $\mathrm{M}_{\mathrm{AGG}}$ & 5'-GATGAGTCCTGAGTAA+AGG-3' \\
\hline $\mathrm{M}_{\mathrm{AAT}}$ & 5'-GATGAGTCCTGAGTAA+AAT-3' \\
\hline $\mathrm{M}_{\mathrm{CTG}}$ & 5'-GATGAGTCCTGAGTAA+CTG-3' \\
\hline
\end{tabular}

\subsection{AFLP Reactions}

Genetic variation in bell pepper was studied according to Vose et al. [23] with some modifications. Approximately $250 \mathrm{ng}(18 \mu \mathrm{l})$ of high molecular DNA was digested in $1.5 \mathrm{ml}$ microfuge tube with $1.25 \mathrm{U} \backslash \mu \mathrm{l}$

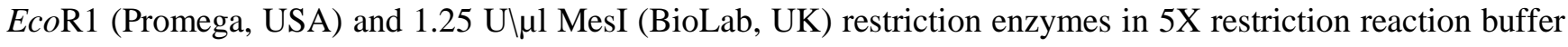
(50 mM Tris- $\mathrm{HCl} \mathrm{pH7.5,} \mathrm{50mM} \mathrm{Mg-acetate,} 250 \mathrm{mM} \mathrm{K}$-acetate) with a final volume of $25 \mu \mathrm{l}$. The reaction was done by incubation at $37^{\circ} \mathrm{C}$ for $2 \mathrm{hrs}$. Then the reaction mixture was incubated $70^{\circ} \mathrm{C}$ for 15 min for restriction enzymes inactivation. Two different adaptors, for EcoRI and MseI, were ligated to the ends of the genomic restriction fragments. The digested and ligated template DNA was pre-amplified using EcoRI+1 and MseI+1 primer in a total volume of $50 \mu \mathrm{l}$ containing $24 \mu \mathrm{l}$ of Adapter/ligation solution $(0.4 \mathrm{mM}$ Adenosine triphosphate,

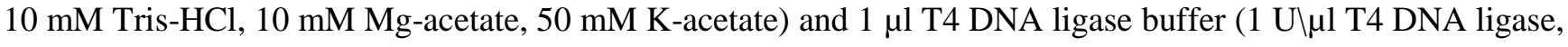
$10 \mathrm{mM}$ Tris- $\mathrm{HCl} \mathrm{pH} 7.5,1 \mathrm{mM}$ Dithiothreitol, $50 \mathrm{mM} \mathrm{KCl,} 0.1 \mathrm{mM}$ EDTA, 50\% Glycerol) to each previous 
reaction $(25 \mu \mathrm{l})$. The reaction was done by incubation at $20^{\circ} \mathrm{C}$ for $2 \mathrm{hrs}$. The completeness of the digestion was checked on a $1.5 \%$ agarose gel. Ligation mixture was diluted 10 times in TE for the pre-selective amplification with $E c o \mathrm{R} 1+\mathrm{A}\left(\mathrm{E}_{\mathrm{A}}\right)$ and Mes $\mathrm{I}+\mathrm{C}\left(\mathrm{M}_{\mathrm{c}}\right)$. Pre-selective amplification was done in $0.2 \mathrm{ml}$ microfuge tube by adding $12.5 \mu 12 X$ PCR Go Taq ${ }^{\circledR}$ Green Master Mix (Promega, USA), $20 \mu 1$ (2.5 pmol) EcoR1+A primer, $20 \mu 1$ (2.5 pmol) MesI+C primer, $5 \mu \mathrm{l}$ ligation mixture in a final volume of $60 \mu \mathrm{l}$. The reaction mixers were placed in thermal cycler (Esco, Singapore), and the amplification profile was $30 \mathrm{sec}$ at $94^{\circ} \mathrm{C}$ incubation, followed by 20 cycles of $30 \mathrm{sec}$ at $94^{\circ} \mathrm{C}$ for denaturation, $60 \mathrm{sec}$ at $56^{\circ} \mathrm{C}$ for annealing and $60 \mathrm{sec}$ at $72^{\circ} \mathrm{C}$ for extension. Quality of the pre-selective amplification was checked on a $1.5 \%$ agarose gel and were then diluted four-fold with TE buffer prior to the selective amplification step. Selective amplification was performed in a $50 \mu \mathrm{l}$ final volume containing $5 \mu \mathrm{l}$ of pre-amplification products, $12.5 \mu \mathrm{l} 2 \mathrm{X}$ PCR Go Taq® Green Master Mix, $20 \mu \mathrm{l}(5 \mathrm{pmol}) \mathrm{E}_{\mathrm{ACG}}$ primer, $20 \mu \mathrm{l}(5 \mathrm{pmol}) \mathrm{M}_{\mathrm{AGG}}$ primer. Another three primer combinations $\mathrm{E}_{\mathrm{AAG}} / \mathrm{M}_{\mathrm{AAT}}$ and $\mathrm{E}_{\mathrm{ACA}} / \mathrm{M}_{\mathrm{CTG}}$ were also used for selective amplifications. The reaction mixers were placed in thermal cycler (Esco, Singapore), and the amplification profile was $3 \mathrm{~min}$ at $94^{\circ} \mathrm{C}, 12$ cycles of $30 \mathrm{sec}$ at $94^{\circ} \mathrm{C}, 30 \mathrm{sec}$ at $65^{\circ} \mathrm{C}$ with decreasing for $0.7^{\circ} \mathrm{C}$ after each cycle down to $55.9^{\circ} \mathrm{C}$ and $60 \mathrm{sec}$ at $72^{\circ} \mathrm{C}$, followed by $35 \mathrm{cycles}$ of $30 \mathrm{sec}$ at $94^{\circ} \mathrm{C}, 30 \mathrm{sec}$ at $55.9^{\circ} \mathrm{C}$ and $60 \mathrm{sec}$ at $72^{\circ} \mathrm{C}$. Amplification products were separated on a $6 \%$ polyacrylamide gel (45 gm (7.5 M) Urea, $15 \mathrm{ml}$ (40\%) Acrylamide:Methylenbisacrylamid (19:1), in $10 \mathrm{ml} \mathrm{10X} \mathrm{TBE,} \mathrm{final} \mathrm{volume} \mathrm{up} \mathrm{to} 100 \mathrm{ml}$ with $\mathrm{ddH}_{2} \mathrm{O}$ ). For $10 \mathrm{ml}$ of this solution $10 \mu \mathrm{l}(10 \%)$ Ammonium persulphate and $30 \mu \mathrm{l}$ Tetramethylethylene diamine (TEMED) was added. Ten micrliter of each amplification product was loaded and equal volume (10 ul) of formamide dye $(98 \%$ formamide, $10 \mathrm{mM}$ EDTA $\mathrm{pH} 8.0$, and $0.005 \%$ bromophenol blue and $0.005 \%$ xylene cyanol as tracking dyes). Then denatured at $94^{\circ} \mathrm{C}$ for $5 \mathrm{~min}$ and placed immediately on ice. About $5 \mu \mathrm{l}$ was loaded onto 6\% polyacrylamide denaturation gel. The DNA $100 \mathrm{bp}$ ladder (Promega, USA) was also loaded on the polyacrylamide gel. The gel electrophoresis was performed by using $75 \mathrm{~V}$ for $3-4 \mathrm{hrs}$ and stained with ethidium bromide (Promega, USA) for $15 \mathrm{~min}$. The gel was documented with gel documentation system (Biocom, USA).

\subsection{Band Scoring and Data Analysis}

The resulted amplified bands by using AFLP marker were converted to two-dimensional matrix. The results between the studied samples were analyzed by using Past software ver. 1.92 [32]. The percentage of polymorphic bands, primer efficiency (number of monomorphic bandsitotal number of bands x 100) and the discriminatory power (number of polymorphic bandsltotal number of bands resulted from all the primer combinations x 100) were calculated. For diversity analysis, bands were scored manually as present (1) or absent (0). Only the clearest and strongest bands were recorded and used for the analysis. A square symmetric matrix of similarity was then obtained with the Jaccard's similarity coefficient. The average similarity matrix was used to generate a tree for cluster analyses by UPGMA (Unweighted Pair Group Method with Arithmetic Mean). Euclidean coefficient was used for genetic distance study.

\section{Results}

\subsection{Amplification of DNA in Pepper Fruit Samples by Using AFLP Marker}

The genetic variation was studied by using AFLP marker for three selective primer combinations $\mathrm{E}_{\mathrm{ACG}} / \mathrm{M}_{\mathrm{AGG}}$, $\mathrm{E}_{\mathrm{AAG}} / \mathrm{M}_{\mathrm{AAT}}$ and $\mathrm{E}_{\mathrm{ACA}} / \mathrm{M}_{\mathrm{CTG}}$. These combinations were produced 15 bands in all the studied samples. The first selective primer combination $\left(\mathrm{E}_{\mathrm{ACG}} / \mathrm{M}_{\mathrm{AGG}}\right)$ produced 4 bands for the studied bell pepper fruits with 3 monomorphic bands in each sample, except the orange and yellow Jordanian bell pepper samples, which produced 4 bands one of them polymorphic band with $25 \%$ ratio and $21.43 \%$ primer efficiency with $100 \%$ discriminatory power. The second selective primer combination $\left(\mathrm{E}_{\mathrm{AAG}} / \mathrm{M}_{\mathrm{AAT}}\right)$ produced 4 monomorphic bands in each sample with no polymorphic bands with $28.57 \%$ primer efficiency and $0 \%$ discriminatory power, whereas the third selective primer combination $\left(\mathrm{E}_{\mathrm{ACA}} / \mathrm{M}_{\mathrm{CTG}}\right)$ produced 7 monomorphic bands in each sample, except the Iraqi/Balad green bell pepper, which produced 3 monomorphic bands with no polymorphic bands and the primer efficiency is $50 \%$ with $0 \%$ discriminatory power (Table 3 , Fig. 1). 
TABLE III: Selective Primer Combinations, Number of Polymorphic Amplicons and Polymorphic Information Content in AFLP Analysis of Bell Pepper

\begin{tabular}{|c|c|c|c|c|c|}
\hline Combination & Mb & $\mathbf{P b}$ & $\mathbf{P b}(\boldsymbol{\%})$ & $\mathbf{P e}$ & $\mathbf{D p}$ \\
\hline $\mathbf{E}_{\mathbf{A C G}} / \mathbf{M}_{\mathbf{A G G}}$ & 3 & 1 & 25 & 21.43 & 100 \\
\hline $\mathbf{E}_{\mathbf{A A G}} / \mathbf{M}_{\mathbf{A A T}}$ & 4 & 0 & 0 & 28.58 & 0 \\
\hline $\mathbf{E}_{\mathbf{A C A}} / \mathbf{M}_{\mathbf{C T G}}$ & 7 & 0 & 0 & 50 & 0 \\
\hline Total & 14 & 1 & - & 100 & 100 \\
\hline
\end{tabular}

Mb: Monomorphic bands, Pb: Polymorphic bands, Pe: Primer efficiency, Dp: Discriminatory power

The decreasing or lack of genetic variation is due to the nature of the auto- pollination of plant classes and also to the genetic basis, as it is known that the plant species with auto- pollination (inoculation) such as tomato Lycopersicon esculentum (belonging to the family Solanaceae) showed the low rate in the morphological diversity in own genome [33], [34], [35]. Kochieva and Ryzhova [13] revealed that the genetic variation was low in the fruits of pepper, they observed that the morphological diversity rate was $16.5 \%$ when using 9 pairs of primers for AFLP technique. Additionally, the low diversity rate was confirmed by [36] when testing samples of Italian peppers and Colombian pepper as well; the low rate of variation suggests a substantial convergence of varieties, as the wild type, which was accession of it, is a limited genepool [28]. Moreover, [29] explained that the low genetic variation in Italian pepper due to the continuous selection for certain types according to the standards prescribed by the breeder. The various geographic regions may contribute to the presence of genetic variation of hereditary between the types of pepper that harvested from several countries while, the genetic variation was less between the types of Ethiopian chili pepper with long fruits as showed in the study of Geleta et al. [11] when using AFLP technique. AFLP technique has many limitations, including in the case that the similarity in nucleotide sequences less than $90 \%$, the selective amplification that used in AFLP technique may contribute in some of the pieces due to the large variation in nucleotide sequences in different samples [37]. Aktas et al. [6] found that the percentage of polymorphism was $26 \%$ and the highest number of bands was up to 60 bands appeared after using selective amplification of $\mathrm{E}_{\mathrm{ACG}} \mathrm{M}_{\mathrm{AGT}}$, and the lowest number of bands was up to 29 bands after using selective amplification $\mathrm{E}_{\mathrm{AAG}} \mathrm{M}_{\mathrm{AAT}}$, and the number of bands was different to the results of the present study after using the same selective amplification as described above, and this is due to the difference in the samples of pepper in both studies in terms of their genotype and the region of collection. Moreover, the reason is related to methods to produce PCR products, as the current study dependent on ethidium bromide dye, which its accuracy less than silver nitrate dye and radioactive labeling. Aktas et al. [6] observed that the difficulty in comparing its results with the results of previous studies is due to the different genotypes of the peppers samples, as well as the different primers of AFLP; the low rate of genetic variation is resulting from the excessive artificial selection of agricultures of pepper, as is the case of pepper cultivated in Turkish Alata Institute. Most varieties of pepper in Turkey are open pollinated and some varieties local landraces are still grown in multiple small farms, according to the consumer's requirements, thus many breeders have switched from growing traditional varieties (types) to the cultivation of commercial pepper with high quality and desired properties [38]. Like this low polymorphism in the studied varieties resulting from limited gene pool of pepper with large fruits, as well as reflects the conservative nature of the pepper genome domesticated due to autopollination (inoculation) [39]. The genetic variation of the Indian and Taiwan pepper was a close in a study using 8 pairs of AFLP primers for 59 genotypes of pepper; 56 of them was $C$. annuum and only three was $C$. baccatum. These primers produced 414 bands, 389 of it was monomorphic and dendrogram put $C$. baccatum in one group while other types were in a separated group included 9 different clusters. It was found by Krishnamurthy et al. [40] that the reason for this finding was to the founder effect and humeral pollination that causes including several genotypes (collected from several geographic locations) in one group [41], [42]. 


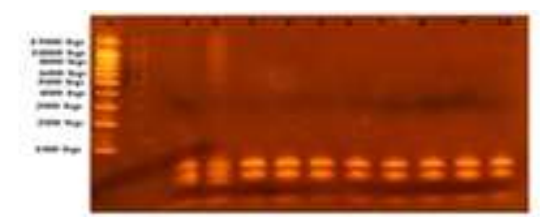

A

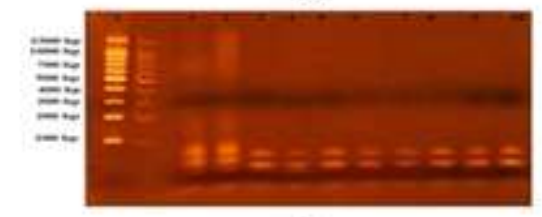

C

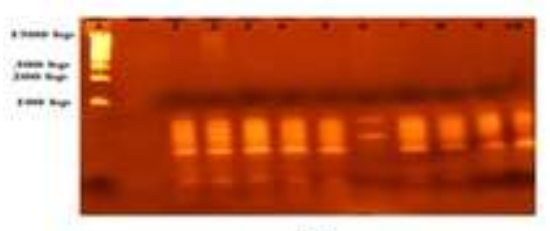

$E$

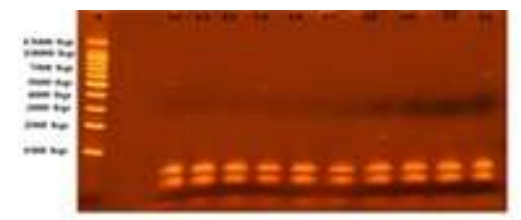

B

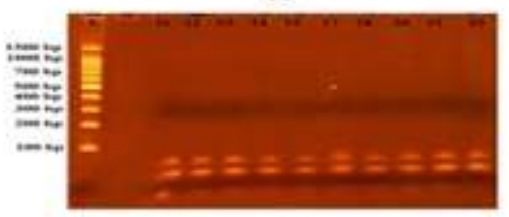

D

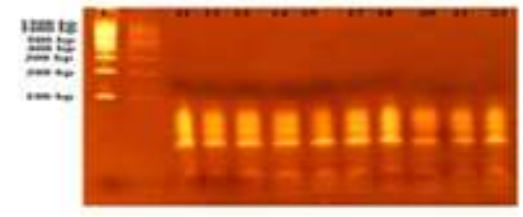

$\mathbf{F}$

Fig. 1: Fingerprinting of 20 samples of bell pepper by AFLP marker using three primer combinations. The PCR products were electrophoresed on 6\% denaturing polyacrylamide gel, 75 Volt for 3-4 hrs. A and B selective primer combination EACG/MAGG, C and D selective primer combination EAAG/MAAT, E and F selective primer combination EACA/MCTG.

Numbers refer to bell pepper samples. 1: Jordanian/orange, 2: Jordanian/red, 3: Jordanian/yellow, 4: Jordanian/green, 5: Spanish/green, 6: Iraqi/Balad green, 7: Iraqi/Yousifia green, 8: Chines/red, 9: Iraqi/Souwyera green, 10: Chines/yellow, 11:

Chines/orange, 12: Spanish long/green, 13: Iranian/red, 14: Iranian/orange, 15: Iranian/yellow, 17: Italy/orange, 18: Italy/yellow, 20: Spanish/red, 21: Spanish long/red, 22: Iranian/green. L: DNA 100 bp ladder.

\subsection{Cluster Analyses of the Bell Peppers Depending on AFLP Marker}

Genetic dendrogram was painted depending on the results which obtained from selective primer combinations results in the studied bell pepper fruits using Jaccard genetic similarity coefficient. The results of UPGMA dendrogram of the studied samples by using Jaccard coefficient for genetic similarity was distributed the studied samples into 3 main groups. The first group was included the red and orange Jordanian bell pepper fruits samples, whereas the second group included the Iraqi/Balad green bell pepper and the third group included the rest samples (Fig. 2). This diagram revealed a high similarity between the Jordanian/red and Jordanian/orange bell pepper (first group) with $0.94 \%$ in comparisons with other samples of bell pepper (third group), while the similarities with the Iraqi/Balad green bell pepper (second group) was $0.68 \%$. However, other samples in the third group showed high similarity with $1 \%$. The present study is first in Iraq that deals with genetic variation in local and imported bell peppers samples by using AFLP marker. Furthermore, due to the absence of the official sources that confirms the country origin of bell pepper samples, it was difficult to compare them with the same fruits in their origin countries, and that requires prospective studies like DNA sequencing of the generated bands which obtained in this study to compare them with the whole genome sequences of bell pepper published in international websites such as http://genome.ucsc.edu and www.ncbi.nlm.nih.gov to detect the origin country of the imported fruits of bell peppers. 


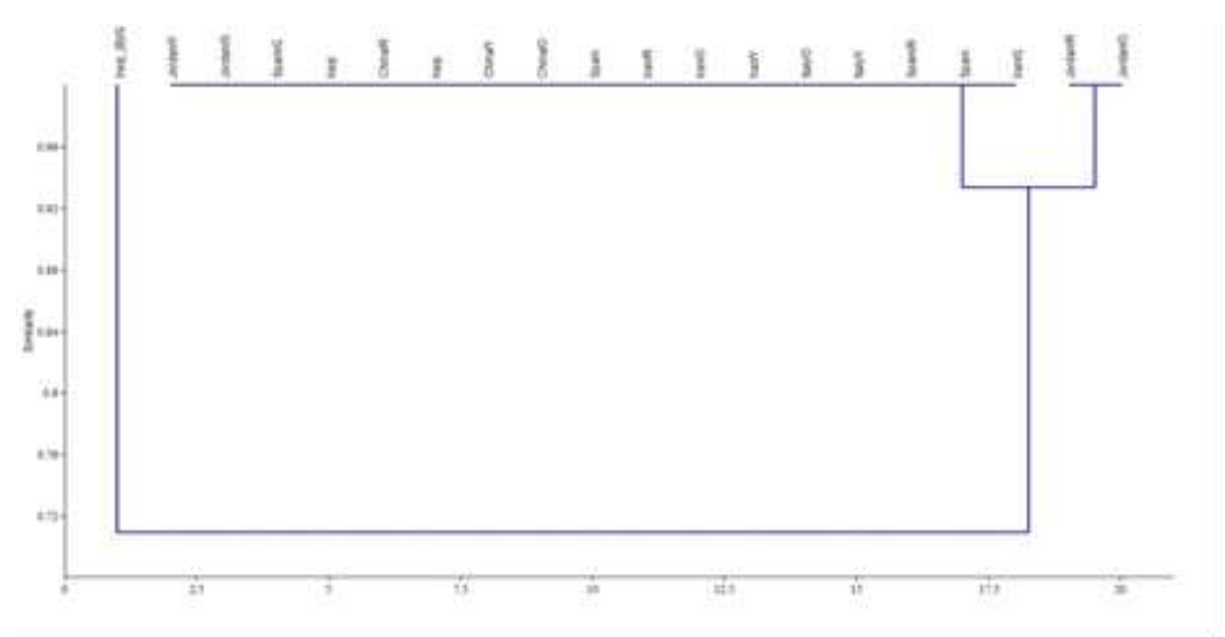

Fig. 2: UPGMA dendrogram of 20 samples of bell pepper constructed based on AFLP marker data generated from three selective primer combinations. High similarity with $1 \%$ between almost bell pepper samples (third group), while the similarity between the Jordanian/red and Jordanian/orange bell pepper (first group) was $0.94 \%$. The similarity of Iraqi/Balad green bell pepper (second group) was $0.68 \%$ when compared with the other samples. Samples from left to right: Iraq_(B)/G: Iraqi/Balad green, Jordan/Y: Jordanian/yellow, Jordan/G: Jordanian/green, Spain/G: Spanish/green, Iraqi: Iraqi/Yousifia green, China/R: Chines/red, Iraqi: Iraqi/Souwyera green, China/Y: Chines/yellow, China/O: Chines/orange, Spain: Spanish long/green, Iran/R: Iranian/red, Iranian/O: Iranian/orange, Iranian/Y: Iranian/yellow, Italy/O: Italy/orange, Italy/Y: Italy/yellow, Spain/R: Spanish/red, Spain: Spanish long/red, Iran/G: Iranian/green, Jordan/R: Jordanian/red, Jordan/O: Jordanian/orange.

Tam et al. [43] made a comparison between AFLP, SSR and sequence specific amplification polymorphism (SSAP) techniques in the detection of genetic variation in 35 lines of the fruits in bell and conical (cone) and chili pepper. The percentage of variation was very low, it was $8.03 \%$ when using 9 selective amplification of AFLP primers, and produced 1432 bands, 115 bands was polymorphic, and this illustrates the limited genetic distance in the fruits of bell pepper, and also the dendrogram separated this type from the another most diverse group which included the conical of and chili pepper. While after comparing the results observed from 3 techniques, SSAP technique has been shown as the best technique to identify genetic variation, followed by SSR technique which was higher than four to nine times more AFLP technique. Bell and long divided into two groups according to the map of the genetic dendrogram and the study included thirty-two accessions using five selective primer combinations of AFLP marker and produced 255 polymorphic bands, and this reflects the breeder's efforts in the development and selection of phenotype in the fruits of pepper [44]. In another study included 45 varieties of local and imported pepper used to estimate the genetic variation between them, in which eight selective amplification used for primers of AFLP technique, resulted in 956 polymorphic bands, and the tree of genetic dendrogram formed different groups with weak differentiation, indicating a low degree of genetic variation that indicated a strong genetic relationship between these species of pepper, as the higher production of pepper in the open land and greenhouses directly depends on a range of varieties without renewal, and this result is consistent with the results of [6], [25].

\subsection{Genetic Distance between the Bell Pepper Samples Depending on the Results of AFLP Marker}

The genetic distance between the bell pepper samples were calculated by using Euclidean coefficient. The results revealed the highest values between red and orange Jordanian bell pepper and the Iraqi/Balad green bell pepper with 2.236 values, while the lowest genetic distance founded between many bell pepper samples with zero value. These results confirmed the fact that the least similarity has the largest genetic variation. The modern breeding of plant led to a significant decreases in the genetic variation of modern varieties [45], and this also explained by Paran et al. [25] when they have a low percentage of the polymorphic varieties (13\%) after using of 10 AFLP primers according to the dendrogram of this study; the large fruit of bell sweet pepper with low genetic variation separated compared to the variation of small fruit with high variation this is similar to the results [43], [46], [47] as well. 
TABLE IV: Genetic Distances among 20 Samples of Bell Pepper Depending on the Results of AFLP Marker

\begin{tabular}{|c|c|c|c|c|c|c|c|c|c|c|c|c|c|c|c|c|c|c|c|c|}
\hline & & & & & & & & & & & & & & & & & & & & \\
\hline Samples & 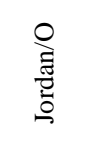 & 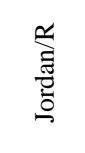 & 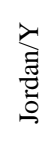 & 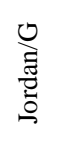 & 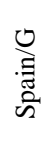 & $\begin{array}{l}\stackrel{Ð}{0} \\
\stackrel{\vec{\Xi}}{\Xi}\end{array}$ & 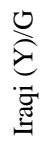 & 节 & 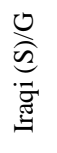 & 㤂 & 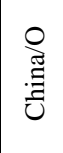 & 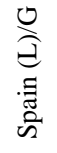 & 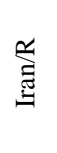 & 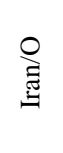 & 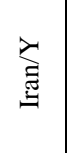 & $\begin{array}{l}\stackrel{\bigcirc}{\lambda} \\
\underset{\Xi}{\Xi}\end{array}$ & 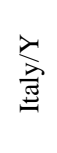 & $\begin{array}{l}\text { In } \\
\text { : } \\
\text { की }\end{array}$ & 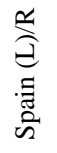 & $\stackrel{Ð}{\Xi}$ \\
\hline Jordan/O & 0 & & & & & & & & & & & & & & & & & & & \\
\hline Jordan/R & 0 & 0 & & & & & & & & & & & & & & & & & & \\
\hline Jordan/Y & 1 & 1 & 0 & & & & & & & & Highe & gene & ic dis & ances & ralues & & & & & \\
\hline Jordan/G & 1 & 1 & 0 & 0 & & & & & & & & & & & & & & & & \\
\hline Spain/G & 1 & 1 & 0 & 0 & 0 & & & & & & & & & & & & & & & \\
\hline Iraqi (B)/G & 2.236 & 2.236 & 2 & 2 & 2 & 0 & & & & & & & & & & & & & & \\
\hline Iraqi $(\mathrm{Y}) / \mathrm{G}$ & 1 & 1 & 0 & 0 & 0 & 2 & 0 & & & & & & & & & & & & & \\
\hline China/R & 1 & 1 & 0 & 0 & 0 & 2 & 0 & 0 & & & & & & & & & & & & \\
\hline Iraqi $(\mathrm{S}) / \mathrm{G}$ & 1 & 1 & 0 & 0 & 0 & 2 & 0 & 0 & 0 & & & & & & & & & & & \\
\hline China/Y & 1 & 1 & 0 & 0 & 0 & 2 & 0 & 0 & 0 & 0 & & & & & & & & & & \\
\hline China/O & 1 & 1 & 0 & 0 & 0 & 2 & 0 & 0 & 0 & 0 & 0 & & & & & & & & & \\
\hline Spain & 1 & 1 & 0 & 0 & 0 & 2 & 0 & 0 & 0 & 0 & 0 & 0 & & & & & & & & \\
\hline Iran/R & 1 & 1 & 0 & 0 & 0 & 2 & 0 & 0 & 0 & 0 & 0 & 0 & 0 & & & & & & & \\
\hline Iran/O & 1 & 1 & 0 & 0 & 0 & 2 & 0 & 0 & 0 & 0 & 0 & 0 & 0 & 0 & & & & & & \\
\hline $\operatorname{Iran} / Y$ & 1 & 1 & 0 & 0 & 0 & 2 & 0 & 0 & 0 & 0 & 0 & 0 & 0 & 0 & 0 & & & & & \\
\hline Italy/O & 1 & 1 & 0 & 0 & 0 & 2 & 0 & 0 & 0 & 0 & 0 & 0 & 0 & 0 & 0 & 0 & & & & \\
\hline Italy/Y & 1 & 1 & 0 & 0 & 0 & 2 & 0 & 0 & 0 & 0 & 0 & 0 & 0 & 0 & 0 & 0 & 0 & & & \\
\hline Spain/R & 1 & 1 & 0 & 0 & 0 & 2 & 0 & 0 & 0 & 0 & 0 & 0 & 0 & 0 & 0 & 0 & 0 & 0 & & \\
\hline Spain (L)/R & 1 & 1 & 0 & 0 & 0 & 2 & 0 & 0 & 0 & 0 & 0 & 0 & 0 & 0 & 0 & 0 & 0 & 0 & 0 & \\
\hline Iran/G & 1 & 1 & 0 & 0 & 0 & 2 & 0 & 0 & 0 & 0 & 0 & 0 & 0 & 0 & 0 & 0 & 0 & 0 & 0 & 0 \\
\hline
\end{tabular}

Jordan/O: Jordanian/orange, Jordan/R: Jordanian/red, Jordan/Y: Jordanian/yellow, Jordan/G: Jordanian/green, Spain/G: Spanish/green, Iraq (B)/G: Iraqi/Balad green, Iraqi (Y): Iraqi/Yousifia green, China/R: Chines/red, Iraqi (S): Iraqi/Souwyera green, China/O: Chines/orange, China/Y: Chines/yellow, Spain (L)/G: Spanish long/green, Iran/R: Iranian/red, Iranian/O: Iranian/orange, Iranian/Y: Iranian/yellow, Italy/O: Italy/orange, Italy/Y: Italy/yellow, Spain/R: Spanish/red, Spain (L)/R: Spanish long/red, Iran/G: Iranian/green

\section{References}

[1] J. Andrews, "Peppers: The domesticated capsicums," Austin: University of Texas Press, 1984.

[2] F. R. da Costa, T. N. S. P. Pereira, A. P. Vitória1, K. P. de Campos, R. Rodrigues, D. H. da Silva, and M. G. Pereira, "Genetic diversity among Capsicum accessions using RAPD markers," Crop Breed. Appl. Biotech., Vol. 6, pp. 18-23, 2006.

[3] W. H. Eshbaugh, "Peppers: History and exploitation of a serendipitous new crop discovery," In Janick J, Simon, J. F., editors. New crops. New York, USA: Wiley 1993, pp. 132-139.

[4] B. Pickersgill, "Genetic resources and breeding of Capsicum spp.," Euphytica, vol. 96, pp. 129-133, 1997.

[5] R. K. Shaha, S. H. Rahman, and A. Asrul, "Bioactive compounds in chilli peppers (Capsicum annuum L.) at various ripening (green, yellow and red) stages," Ann. Bio. Res., vol 4, no. 8, pp. 27-34, 2013.

[6] H. Aktas, K. Abak, and S. Sensoy, "Genetic diversity in some Turkish pepper (Capsicum annuum L.) genotypes revealed by AFLP analyses," African J. Biotech., vol 8, no. 18, pp. 4378-4386, 2009.

[7] K. Sitthiwong, T. Matsui, S. Sukprakarn, N. Okuda, and Y. Kosugi, "Classification of pepper (Capsicum annuum L.) accessions by RAPD analysis," Biotechnology, vol. 4, no. 4 pp. 305-309, 2005.

[8] S. Kumari, "Genetic variability studies in bell pepper (Capsicum annuum L.)," Asian J. Horticulture, vol. 8, no. 1, pp. 280-284, 2013.

[9] K. Arumuganathan, and E. Earle, "Nuclear DNA content of some important plant species," Plant Mol. Bio. Reporter, vol. 9, pp. 208-218, 1991.

[10] E. A. Moscone, M. Baranyi, I. Ebert, J. Greilhuber. F., et al. Ehrendorfer, "Analysis of nuclear DNA content in Capsicum (Solanaceae) by flow cytometry and feulgen densitometry," Ann. Bot., vol. 92, pp. 21-29, 2003. 
[11] L. F. Geleta, M. T. Labuschagne, and C. D. Viljoen, "Genetic variability in pepper (Capsicum annuum L.) estimated by morphological data and amplified fragment length polymorphism markers," Biodivers Conserv., vol. 14, pp. 23612375. doi:10.1007/s10531-004-1669-9, 2005.

[12] S. L. Krishnamurthy, A. M. Rao, M. K. Reddy, S. Reddy, S. Ramesh, S. Hittalmani, and M. G. Rao, "Limits of parental divergence for the occurrence of heterosis through morphological and AFLP marker in chili Capsicum annuит L.," Curr. Sci., vol. 104, no. 6, pp. 738-746, 2013.

[13] E. Z. Kochieva, and N.N. Ryzhova, "Molecular AFLP analysis of the genotypes of pepper Capsicum annuum cultivars," Russian J. Genet., vol. 39, no. 12, pp. 1345-1348, 2003.

[14] B. Pickersgill, "Chromosomes and evolution in Capsicum,". In Capsicum 77. Edited by E. Pochard. INRA MontfavetAvignon, France, 1977.

[15] R. J. Jensen, M. J. McLeod, W. H. Eshbaugh, and S. I. Guttman, "Numerical taxonomic analyses of allozymic variation in Capsicum (Solanaceae)," Taxonomy, vol. 28, pp. 315-327, 1979.

[16] R. C. Panda, O. A. Kumar, K. G. Raja Rao, "The use of seed protein electrophoresis in the study of phylogenetic relationships in chili pepper (Capsicum L.)," Theor. Appl. Genet., vol. 72, pp. 665-670, 1986.

[17] C. Conicella, A. Errico, and F. Saccardo, "Cytogenetic and isozyme studies of wild and cultivated Capsicum annuum," Genome, vol. 33, pp. 279-282, 1990.

[18] P. Belletti, S. Lanteri, F. Saracco, "Allozyme variability in Capsicum,". In: Proceedings of the Eighth Meeting on Genetics and Breeding on Capsicum and Eggplant, Rome, Italy, 7-10 September 1992, pp. 221-226.

[19] A. Posch, B. M. Van den Berg, C. Duranton, A. Görg, "Polymorphism of pepper (Capsicum annuum L.) seed proteins studied by two dimensional electrophoresis with immobilized pH gradients: methodical and genetic aspects," Electrophoresis, vol. 15, pp. 297-304, 1994.

[20] C. Lucchese, G. Dinelli, A. Miggiano, A. Lovato, "Identification of pepper (Capsicum spp.) cultivars by field and electrophoresis tests," Seed Sci. Technol., vol. 27, pp. 37-47, 1999.

[21] P. G. C. Odeigah, B. Oboh, I. O. Ahhalokpe, "The characterization of Nigerian varieties of pepper, Capsicum annuum, and Capsicum fructescens by SDS-polyacrylamide gel electrophoresis of seed proteins," Genet. Res. Crop Evol., vol. 46, pp. 127-131, 1999.

[22] F. Loaiza-Figueroa, K. Ritland, J. A. Laborde-Cancino, and S. D. Tanksley, "Patterns of genetic variation of the genus Capsicum (Solanaceae) in Mexico," Plant Syst. Evol., vol. 165, pp. 159-188,1989.

[23] P. Vos, R. Hogers, M. Bleeker, M. Reijanas, T. V. de Lee, M. Hornes, A. Frijters, J. Pot, J. Peleman, M. Kuiper, and M. Zabeau, "AFLP: a new technique for DNA fingerprinting," Nucleic Acid Res., vol. 23, no. 21, pp. 4407-4414, 1995.

[24] S. Kafkas, H. Ozkan, and M. Sutyemez, "DNA polymorphism and assessment of genetic relationships in Walnut genotypes based on AFLP and SAMPL markers," J. Amer. Soc. Hort. Sci., vol. 130, no. 4, pp. 585-590, 2005.

[25] I. Paran, E. Aftergoot, C. Shifriss, "Variation in Capsicum annuum revealed by RAPD and AFLP markers," Euphytica, vol. 99, pp. 167-173,1998.

[26] A. Ben-Chaim, R. C. Grube, M. Lapidot, M. Jahn, and I. Paran, "Identification of quantitative trait loci associated with resistance to cucumber mosaic virus in Capsicum annuum," Theor. Appl. Genet., vol. 102, pp. 1213-1220, 2001.

[27] S. Lanteri, and G. Barcaccia, "Molecular marker based analysis for crop germplasm preservation,". In: Ruane, J., Sonnino, A. (Ed.). The role of biotechnology in exploring and protecting agricultural genetic resources .Rome: FAO., 2006, pp. 55-66.

[28] S. P. Toquica, F. Rodriquez, E. Martinez, M. C. Duque, J. Tohme, "Molecular characterization by AFLPs of Capsicum germplasm from the Amazon department in Columbia, characterization by AFLPs of Capsicum," Genet. Res. Crop Evol., vol. 50, pp. 639-647, 2003. 
[29] E. Portis, A. Acquadro, C. Comino, and S. Lanteri, "Effect of farmer's seed selection on genetic variation of landrace population of pepper (Capsicum аппиит L.), grown in North-west Italy," Genet. Res. Crop Evol., vol. 51, pp. 581-590, 2004.

[30] [30] T. J. Kang, and M. S. Yang, "Rapid and reliable extraction of genomic DNA from various wild-type and transgenic," BMC Biotechnol., vol. 4, no. 20, pp. 1-12, 2004.

[31] S. Sensoy, H. Aktas, and K. Abak, "Genetic diversity in some Turkish pepper (Capsicum annuum L.) genotypes revealed by AFLP analyses," African J. Biotechnol., vol. 8, no. 18, pp. 4378-4386, 2009.

[32] Ø. Hammer, D. A.T. Harper, and P. D. Ryan, "PAST: Palaeontological statistics software package for education and data analysis," Paleontologia Eletronica, vol. 4, no. 1, pp. 1-9, 2001.

[33] E. Hiroaki, I. Hiroyuki, T. Tadashi, and I. Shigera, "Genetic diversity of the peruvianum complex (Lycopersicon peruvianum L. Mill and Lycopersicon chilense Dun.) revealed by RAPD analysis," Euphytica, vol. 116, pp. 23-31, 2000.

[34] H. P. Young, A. L. Marilyn, M. A. West, and D. A. Stclair, "Evaluation of AFLPs for germplasm finger printing and assessment of genetic diversity in cultivars of tomato (Lycopersicon esculentum)," Genome, vol. 47, pp. 510-518, 2004.

[35] S. Garcia-Martinez, L. Andreani, M. Garcia- Gusano, F. Geuna, and J. J. Ruiz, "Evaluation of Amplified fragment length polymorphism and simple sequence repeats for tomato germplasm finger printing: utility for grouping together closely related traditional cultivars," Genome, vol. 49, pp. 648-656, 2006.

[36] S. Lanteri , A. Acquadro, L. Quagliotti, and E. Portis, "RAPD and AFLP assessment of genetic variation in a landrace of pepper (Capsicum annuum L.), grown in North-west Italy," Genet. Res. Crop Evol., vol. 50, pp. 723-735, 2003.

[37] M., Vuylsteke, J. D. Pelema, and M. J. T. VanEijk, "Technology for DNA finger printing," Nature protocols, vol. 2, pp. 1387-1398, 2007.

[38] M. K. Bozokalfa, D. Esiyok, and K. Turhan, "Patterns of phenotypic variation in a germplasm collection of pepper (Capsicum annuиm L.) from Turkey," Spanish J. Agri. Res., vol. 7, no. 1, pp. 83-95, 2009.

[39] E. A. Snigir, O. N. Pyshnaya, E. Z. Kochieva, and N. N. Ryzhova, "AFLP-analysis of varietal polymorphism in Capsicum annuum L.," Selskokhozyaistvennaya Biologiya (Agricultural Biology), vol. 1, pp. 53-60, 2013.

[40] S. L. Krishnamurthy, Y. Prashanth, A. M. Rao, K. M. Reddy, and R. Ramachandra, "Assessment of AFLP marker based genetic diversity in chilli (Capsicum annuum L.\& C. baccatum L.)," Indian J. Biotech., Vol. 14, pp. 49-54, 2015.

[41] J. Baral, and P. W. Bosland, "Genetic diversity of capsicum germ plasm collection from Nepal as determined by randomly amplified polymorphic DNAmarkers," J. Am. Soc. Hortic. Sci., vol. 127, pp. 316-324, 2002.

[42] S. T. Thul, R. K. Lal, A. K. Shasany, M. P. Darokar, A. K. Gupta, M. M. Gupta, R. K. Verma, and S. P. S Khanuja, "Estimation of phenotypic divergence in a collection of Capsicum specie for yield related traits," Euphytica, vol. 168, pp. 189-196, 2009.

[43] S. M. Tam, C. Mhiri, A. Vogelaar, M. Kerkveld, S. R. Pearce, and M. A. Grand Bastien, "Comparative analyses of genetic diversities within tomato and pepper collections detected by ret transposon- based SSAP, AFLP and SSR," Theor .Appl. Genet., vol. 110, pp. 819-831, 2005.

[44] Y. Wahyuni, A. R. Ballester, Y. Tikunov, R. C. H. Devos, K. T. B. Pelgrom, A. Maharijaya, E. Sudarmonowati, R. J. Bino, and A. G. Bovy, "Metabolomics and molecular marker analysis to explore pepper (Capsicum sp.) biodiversity," Metabolomics, vol. 9, no. 1, pp. 130-144, 2013.

[45] R. Vellve, "The decline of diversity in European agriculture," Ecologist, vol. 23, pp. 64-69, 1993.

[46] V., Lefebvre, A. Palloix, and M. Rives, "Nuclear RFLP between pepper cultivars (Capsicum annuum L.)," Euphytica, vol. 71, pp. 189-199, 1993.

[47] V. Lefebvre, B. Goffinet, J. C. Chauvet, B. Caromel, P. Signoret, R. Brand, and A. Palloix, "Evaluation of genetic distances between pepper inbred lines for cultivar protection purposes: comparison of AFLP, RAPD and phenotypic data,". Thero Appl. Genet., vol. 102, pp. 741-750, 2001. 